OPEN ACCESS

Edited by:

Youji Wang,

Shanghai Ocean University, China

Reviewed by:

Guangxu Liu,

Zhejiang University, China

Maurizio Manera,

Università di Teramo, Italy

${ }^{*}$ Correspondence:

Yongbo Bao

bobbao2001@gmail.com

Specialty section:

This article was submitted to

Aquatic Physiology,

a section of the journal

Frontiers in Physiology

Received: 27 March 2018

Accepted: 29 June 2018

Published: 20 July 2018

Citation:

Song D, Lin Z, Yuan Y, Qian G, Li C and Bao Y (2018) DPEP1 Balance GSH Involve in Cadmium Stress

Response in Blood Clam Tegillarca granosa. Front. Physiol. 9:964 doi: 10.3389/fphys.2018.00964

\section{DPEP1 Balance GSH Involve in Cadmium Stress Response in Blood Clam Tegillarca granosa}

\author{
Danli Song ${ }^{1,2}$, Zhihua Lin'1, Yongjun Yuan', Guang Qian ${ }^{1,2}$, Chenghua $L i^{2}$ and \\ Yongbo Bao ${ }^{1 *}$
}

'Zhejiang Key Laboratory of Aquatic Germplasm Resources, College of Biological \& Environmental Sciences, Zhejiang Wanli University, Ningbo, China, ${ }^{2}$ School of Marine Sciences, Ningbo University, Ningbo, China

The blood clam, Tegillarca granosa, is a benthic filter feeder with a strong capacity to accumulate and tolerate cadmium (Cd). In our previous study, DPEP1 was shown to be significantly up-regulated under $\mathrm{Cd}$ stress based on proteomic analysis. To investigate whether DPEP1 is involved in Cd-induced response, the function of DPEP1 in T. granosa was investigated by integrated molecular and protein approaches. Rapid amplification CDNA end (RACE) assay was established to achieve the complete cDNA sequence of DPEP1 from T. granosa. The full-length cDNA of DPEP1 was $1811 \mathrm{bp}$, and it contained a 1359-bp open reading frame (ORF), including a 22-amino acid signal peptide. qRT-PCR analysis revealed that DPEP1 was expressed in all examined tissues with the highest expression in gills. At the same time, we investigated DPEP1 gene expression changes after $\mathrm{Cd}$ stress at different time points over $96 \mathrm{~h}$. We found that the expression of DPEP1 increased upon initial Cd stress, then it was inhibited, and finally, it was maintained at a low level. Moreover, recombinant DPEP1 showed that higher glutathione (GSH) hydrolysis activity in the temperature range of $30-40^{\circ} \mathrm{C}$, and its maximum activity was at $\mathrm{pH}=6$. Additionally, the results of immunohistochemistry also confirmed that DPEP1 protein was expressed in all test tissues with the highest expression in gills. In addition, there was a positive correlation between QRT-PCR and immunohistochemistry. These results suggested that DPEP1 is probably involved in $\mathrm{Cd}$-induced response by balancing GSH.

Keywords: Tegillarca granosa, DPEP1, cadmium, enzyme activity, immunohistochemistry

\section{INTRODUCTION}

Cadmium (Cd), as a non-essential metal, cannot be degraded or bio-transformed; therefore, it can be easily assimilated, stored, and accumulated, causing a wide range of damage to the organism (Henson and Anderson, 2000; Nasreddine and Parent-Massin, 2002; Cuypers et al., 2010; Hwang et al., 2010). The blood clam Tegillarca granosa, which is a commercial benthic bivalve, has a strong ability to accumulate and tolerate $\mathrm{Cd}$. In addition, its $\mathrm{Cd}$ accumulation capacity is higher than that of oysters and mussels (Gong et al., 2011). Due to the special accumulation and detoxification abilities of T. granosa, many studies have been conducted on its immune response after Cd stress in recent decades. A study found that the accumulation of $\mathrm{Cd}$ in $T$. granosa was highest in the mantle membrane and that it increased with the duration of exposure (Wang et al., 2013). The 96-h short-term lethal concentration $\left(\mathrm{LC}_{50}\right.$ ) of $\mathrm{Cd}$ for $T$. granosa is approximately $6 \mathrm{mg} / \mathrm{L}$, and $\mathrm{Cd}$ can 
cause gonad, foot, mantle membrane-specific organ lesions (Liu et al., 2012; Wang et al., 2014). In addition, findings suggest that some miRNAs and their target genes and pathways may play critical roles in the response to Cd stress (Bao et al., 2014). At the same time, many cadmium-related genes and their response to Cd stress in T. granosa have been studied (Zhou et al., 2013; Li et al., 2015; Cheng et al., 2016; Chen et al., 2017; Qian et al., 2017). Despite many studies on Cd-induced toxicological effects, the mechanisms of Cd-induced reaction are still poorly understood.

Dipeptidase 1 (DPEP1), also known as dehydropeptidase-I, microsomal dipeptidase (MDP) or renal dipeptidase, is a zinc-dependent metalloproteinase that has been shown to process antibiotics, hydrolyze a variety of peptides, including glutathione (GSH) and its conjugates, and participate in leukotriene metabolism (Kozak and Tate, 1982; Nakagawa et al., 1992). Recently, research on DPEP1 has mainly focused on its impact on cancer. Studies have shown that DPEP1 affects the invasion of cancer cells, and because the expression of DPEP1 decreases with pathological differentiation, it can be used as a genetic marker for the treatment of cancer (Okamoto et al., 2011; Eisenach et al., 2013; Tachibana et al., 2017). A study found that changes in DPEP1 expression can lead to an imbalance of (GSH) (Zhang et al., 2012). GSH is one of the most important antioxidants in cells (Meister, 1994). It plays an important role in maintaining normal redox status and antioxidant defense in the body (Ercal et al., 2001). In addition, toxic metal ions can be excreted by binding to GSH to form complexes (Vethanayagam et al., 1999). It has been found that GSH can be combined with Cd to form a certain complex in detoxification (Peng, 2014). In rats, GSH levels decreased in the liver after exposure to a high concentration of $\mathrm{Cd}$, whereas it increased in liver and kidney after exposure to a low concentration of Cd (Bagchi et al., 1996; Karmakar et al., 1998; Liu et al., 2001). In the fish Tilapia nilotica, the content of GSH experienced similar changes to those in rats after Cd stress (Hui et al., 2001). In a teleost hepatoma cell line, the treatment of cells with $10 \mu \mathrm{M} \mathrm{CdCl}$ led to significant increases in GSH (Schlenk and Rice, 1998). In the mollusk Anodonta woodiana, GSH is also sensitive to Cd-induced injury and decreased in gills and liver after high concentration of Cd stress (Yang et al., 2015). It indicated that the change of GSH content is an adaptive regulation of $\mathrm{Cd}$ exposure. Thus, DPEP1 may be involved in Cd stress defense by hydrolyzing GSH.

In our previous work, a regulation network of $T$. granosa in response to cadmium toxicity was constructed with both metabolic and proteomic data. In addition, it suggested a potential toxicological pathway for $\mathrm{Cd}$ and the discovery of many related functional genes (Bao et al., 2016). Glycolysis, sulfur metabolic process, and $\mathrm{Ca}^{2+}$ homeostasis were detected in the study, and these processes were connected with the core network. We found that DPEP1 was the core protein in sulfur metabolic processes and $\mathrm{Ca}^{2+}$ homeostasis by iTRAQ proteome analysis. And it was significantly up-regulated after $250 \mu \mathrm{g} / \mathrm{L} \mathrm{Cd}$ challenge. According to previous studies, Cd has immunotoxicity to the blood clam and it may enter the tissue through $\mathrm{Ca}^{2+}$ channel (Shi et al., 2016, 2018). And it is generally agreed that oxidative stress plays an important role in acute Cd poisoning (Pathak and Khandelwal, 2006), and Cd exposure can alter the antioxidant enzyme activities in blood clam (Peng et al., 2015). In addition, some studies have shown that there is a correlation between sulfate metabolism and Cd (Clemens, 2006). So DPEP1 plays an important role in Cd stress response.

To explore the role of DPEP1 in Cd stress, we first cloned the DPEP1 genes of T. granosa and analyzed their expression in different configurations and times after $\mathrm{Cd}$ stress by qRT-PCR. Then, recombinant DPEP1 was overexpressed and purified using pET-32a (+) expression vector in Escherichia coli, and the activity of purified DPEP1 was assessed. Additionally, the expressions of DPEP1 in various tissues and at different times after $\mathrm{Cd}$ stress were examined by immunohistochemistry. This work preliminarily explored the related mechanism of DPEP1 on Cd defense in T. granosa, generating important information that can help with our understanding of the mechanism of cadmium detoxification in T. granosa.

\section{MATERIALS AND METHODS}

\section{Experimental Animals and Sampling}

Healthy and consistently sized (average shell length of approximately $30 \mathrm{~mm}$ ) $T$. granosa were collected from an aquaculture farm (Ningbo, China) and acclimatized in $10 \mathrm{~L}$ of aerated natural seawater $\left(28 \pm 2 \%\right.$ salinity, $25 \pm 2{ }^{\circ} \mathrm{C}$, and less than $0.08 \mu \mathrm{g} / \mathrm{L} \mathrm{Cd)} \mathrm{for} 7$ days. The seawater added with Chaetoceros stock was changed daily. During acclimatization and experimentation, there was no death in the clams.

For analysis of the tissue distribution of DPEP1 mRNA, the gill, adductor muscle, blood, viscera, foot, mantle, and gonad of five clams were collected, and each tissue sample was mixed in a $1.5-\mathrm{mL}$ tube. We performed three replicates with three different tissue mixtures, and all samples were flash-frozen in liquid nitrogen and stored at $-80^{\circ} \mathrm{C}$ for RNA extraction and cDNA synthesis.

For the Cd challenge experiment, 260 clams were divided into two groups, and one group was exposed to $\mathrm{Cd}^{2+}\left(\mathrm{CdCl}_{2}\right)$ with a final gradient concentration of $25 \mu \mathrm{g} / \mathrm{L}$. Another group was exposed to $250 \mu \mathrm{g} / \mathrm{L} \mathrm{Cd}^{2+}$. After $0,3,6,9,12,24,48$, and $96 \mathrm{~h}$ of exposure, the blood and gill tissue of T. granosa were collected to temporal expression analysis. Each time point takes 15 T. granosa and divides the tissues into three groups for mixing. In addition, $0 \mathrm{~h}$ served as the control group. We performed three replicates with three different tissue mixtures, and all samples were flash-frozen in liquid nitrogen and stored at $-80^{\circ} \mathrm{C}$ for RNA extraction and cDNA synthesis.

For the immunohistochemistry experiment, T. granosa was exposed to $25 \mu \mathrm{g} / \mathrm{L} \mathrm{Cd}^{2+}$. After 0,12 , and $96 \mathrm{~h}$ of exposure, the gill tissues of three $T$. granosa were randomly sampled. In addition, the adductor muscle, viscera, foot, and mantle of three T. granosa at $0 \mathrm{~h}$ were collected. All tissues were fixed in 10\% neutral buffered formalin, conventional methods of dehydration were applied, and the samples were paraffin-embedded and sliced (Love et al., 2003). 


\section{Cloning and Analysis of the Full-Length CDNA of DPEP1}

Total RNA was extracted from T. granosa using RNAiso plus (Takara, Japan) according to the manufacturer's instructions. RNA quality was assessed by electrophoresis on $1 \%$ agarose gels and quantified spectrophotometrically with a NanoDrop 2000 UV-Vis Spectrophotometer (Thermo Scientific). The full-length cDNA sequence of DPEP1 was synthesized from high-quality total RNA using a SMARTer ${ }^{\mathrm{TM}}$ Rapid amplification $\mathrm{CDNA}$ end (RACE) cDNA Amplification Kit (Takara, Japan). The partial cDNA sequence of DPEP1 was extracted from our finished transcriptome data of T. granosa, and gene specific primers (Table 1) were designed for a $5^{\prime}$ and $3^{\prime}$ RACE experiment. The PCR products were purified using a Gel Extraction Kit (Omega, United States), cloned into the pMD18-T simple vector (Takara, Japan), and transformed into E. coli DH5 $\alpha$ cells (Takara, Japan) according to the supplied protocols. Then the three positive clones for each product were sequenced at Invitrogen (Shanghai, China).

The cDNA sequence of DPEP1 was determined using the BLAST at the National Center for Biotechnology Information ${ }^{1}$, and the amino acid sequence was deduced using the Expert Protein Analysis System². The molecular mass (MM) and theoretical isoelectric point (pI) of DPEP1 were calculated using the ProtParam tool ${ }^{3}$. The transmembrane region was predicted using the TMHMM Server v. $2.0^{4}$. Domains were detected by the simple modular architecture research tool program $^{5}$, and multiple alignments analysis of each protein was performed by the Clustal Omega Multiple Alignment program ${ }^{6}$.

\section{RNA Isolation and Real-Time Quantitative PCR}

Total RNA was isolated using the RNAiso Plus (TaKara), and its quality was checked by gel electrophoresis and measured A260/A280 with a NanoDrop 2000 UV-Vis Spectrophotometer (Thermo Scientific). Then total RNA was treated DNase to remove contaminated genomic DNA. Total cDNAs were

\footnotetext{
${ }^{1}$ http://www.ncbi.nlm.nih.gov/blast

${ }^{2} \mathrm{http}: / /$ www.expasy.org/

${ }^{3} \mathrm{http}: / /$ www.expasy.ch/tools/protparam.html

${ }^{4}$ http://www.cbs.dtu.dk/services/TMHMM/

${ }^{5} \mathrm{http} / / /$ smart.embl-heidelberg.de/

${ }^{6} \mathrm{http}: / /$ www.ebi.ac.uk/clustalw/
}

TABLE 1 | Primers and interference sequence information in the present study.

\begin{tabular}{lll}
\hline Primer & Sequence $\left(\mathbf{5}^{\prime} \mathbf{-} \mathbf{3}^{\prime}\right)$ & Used for \\
\hline DPEP1-3 & GGCAAATGCGACAGTTACCAG & 3'RACE \\
DPEP1-5 & GCATTGTGGTGTCTCTCTCAGGTTG & 5'RACE \\
DPEP1-1 & GGCAAATGCGACAGTTACCAGG & Real-time PCR \\
DPEP1-2 & GCCCAAAACTGTGCTCCAACCA & \\
Tg-18sRNA & CTTCAAATGTCTGCCCTATCAACT & Real-time PCR \\
Tg-18sRNA & TCCCGTATTGTTTITTCGTCACT & \\
DPEP1-F & GGATCCGCTGACAGTTGGAAAGTGAT & Protein fragment \\
DPEP1-R & CTCGAGAAAGTTGTGTTACATGGAAGG & amplification
\end{tabular}

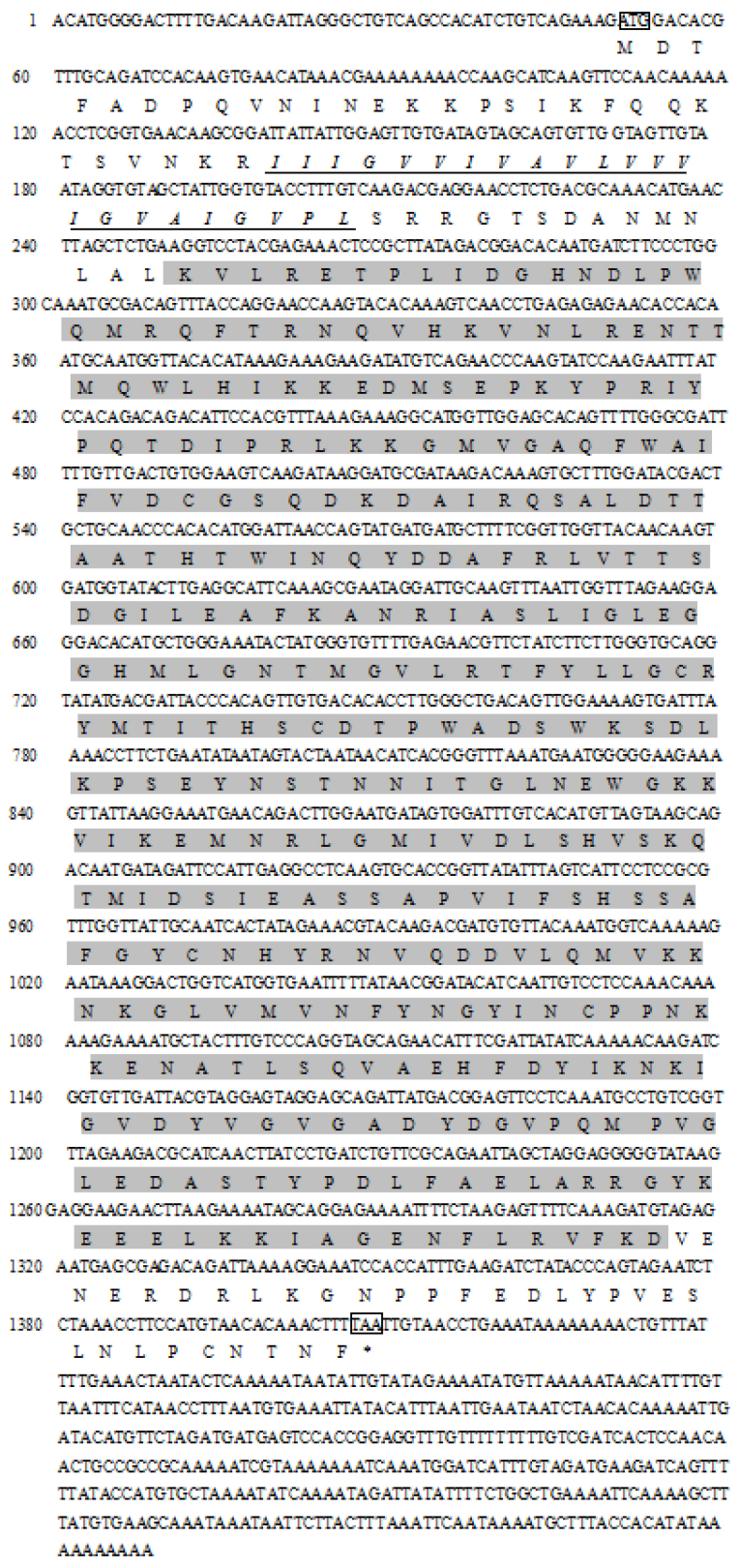

FIGURE 1 | Complete cDNA sequences of DPEP1 from Tegillarca granosa and deduced amino acid sequences. The deduced amino acid sequence is shown below the nucleotide sequence in single letter code, and the predicted transmembrane region sequence is indicated with italics and underlined letters. The start and stop codons and tailing signal are framed. The shadowed part belongs to the domain of peptidase family M19.

synthesized with $1000 \mathrm{ng}$ of total RNAs in a final volume of $20 \mu \mathrm{l}$ using the Prime Script ${ }^{\mathrm{TM}}$ RT reagent kit (Takara) according to the manufacturer's instruction and stored at $-20^{\circ} \mathrm{C}$ before analysis. A real-time quantitative PCR experiment was performed on an ABI 7500 Fast (Thermo Fisher Scientific) with the synthesized total cDNA as a template, and primers specific to DPEP1 were designed using the Primer5 program (Table 1). The reactions were performed in a total volume of $20 \mu \mathrm{L}$ with $10 \mu \mathrm{L}$ of SYBR 


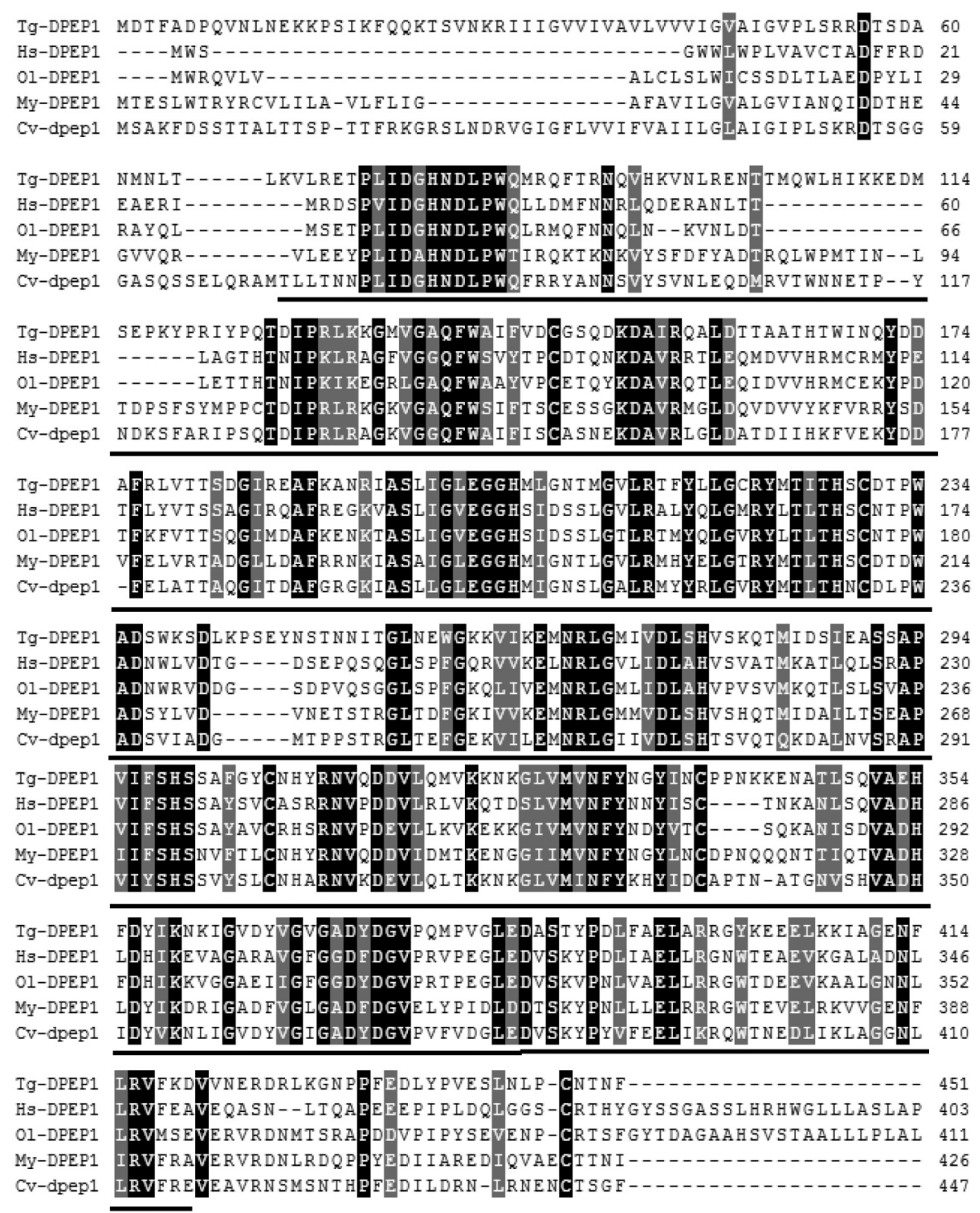

FIGURE 2 | Multiple sequence alignment of DPEP1 from T. granosa (Tg-DPEP1) with other known DPEP1 amino acid sequences: Homo sapiens (Hs, CAG33685.1), Oryzias latipes (OI, XP_004067177.1), Mizuhopecten yessoensis (My, XP_021371422.1), and Crassostrea virginica (Cv, XP_022307112.1). Identities are shaded dark, and similarities are shaded gray. The DPEP1 domain regions are underlined.

Green PCR Master Mix (TaKara), $2 \mu \mathrm{L}$ of cDNA, $1 \mu \mathrm{L}$ of each primer $(10 \mu \mathrm{M})$, and $6 \mu \mathrm{L}$ of RNase-free water. The cycling conditions were $94^{\circ} \mathrm{C}$ for $15 \mathrm{~min}$, followed by 40 cycles of $94^{\circ} \mathrm{C}$ for $15 \mathrm{~s}, 60^{\circ} \mathrm{C}$ for $20 \mathrm{~s}$, and $70^{\circ} \mathrm{C}$ for $25 \mathrm{~s}$. Melting analysis of the amplified products was performed at the end of each PCR cycle to confirm that a single PCR product was produced and detected. The $18 \mathrm{~S}$ rRNA expression was served as an internal reference under the same conditions with primers shown in Table 1. Each sample was analyzed in triplicate. The $2^{-\Delta \Delta C T}$ method was used to determine the relative expression levels of the measured genes (Livak and Schmittgen, 2001). The data were presented as relative mRNA expression levels (means $\pm \mathrm{SD}$, $n=3)$.

\section{Generation of Recombinant DPEP1 in Vitro}

The coding region of DPEP1 without the transmembrane region was amplified by PCR with specific primers (Table 1). The PCR fragment and pET-32a (Novagen, United States) were digested by restriction endonucleases $\mathrm{BamH1}$ and Xhol (NEB, United States) and then ligated them. Then the recombinant plasmid (pET-32a-DPEP1) was transformed into 
E. coli Rosetta (DE3). Positive transformants were incubated in $\mathrm{LB}$ medium containing $100 \mathrm{mg} / \mathrm{mL}$ ampicillin at $37^{\circ} \mathrm{C}$ with shaking at $200 \mathrm{rpm}$. When the culture media reached the $\mathrm{OD}_{600}=0.5-0.8$, the final concentration of $1.0 \mathrm{mM}$ isopropyl $\beta$-D-1-thiogalactopyranoside (IPTG) was added into the LB medium and incubated at $37^{\circ} \mathrm{C}$ with shaking at $200 \mathrm{rpm}$ for $4 \mathrm{~h}$. After induction, the bacteria were collected by centrifugation at $10000 \mathrm{rpm}$ for $10 \mathrm{~min}$ and then resuspended in inclusion washing buffer for sonication treatment. The supernatant and precipitate was obtained by centrifugation at $12000 \mathrm{rpm}$ for $30 \mathrm{~min}$. The precipitate was then re-suspended with inclusion lysate solution and sonicated to collect the supernatant for the second time. The recombinant protein of DPEP1 was purified by a Ni-NTA Sepharose column (Sangon Biotech, Shanghai). The recombinant protein was analyzed by SDS-PAGE to verify purity. The concentration of recombinant protein was quantified by BCA assay using the PierceTM BCA Protein Assay Kit (Thermo scientific, United States) according to the manufacturer's instructions.

\section{Enzyme Activity Assay of DPEP1}

The enzyme activity assay of recombinant DPEP1 protein was carried out with GSH as the substrate and 5,5'-dithiobis(2-nitrobenzoic acid) (DTNB) as the chromogenic agent. Stock solutions of DTNB at $4 \mathrm{mM}$ (Solarbio, China) were dissolved in $0.1 \mathrm{~mol} / \mathrm{L}$ sodium phosphate buffer and prepared $500 \mu \mathrm{g} / \mathrm{mL}$ GSH before using. Measurements were performed by mixing $10 \mu \mathrm{L}$ of $\mathrm{GSH}$ and $10 \mu \mathrm{L}$ of $1 \mathrm{mg} / \mathrm{mL}$ recombinant protein in 96-well plate for $30 \mathrm{~min}(n=10)$, then adding $180 \mu \mathrm{L}$ of DTNB. After brief shaking to mix thoroughly, the mixture was measured continuously for $1 \mathrm{~min}$ at room temperature for absorbance at $422 \mathrm{~nm}$ using a Spectra Max 190 (Molecular Devices, United States). The optimal temperature for enzyme activity was determined by measuring the activities at temperatures between 4 and $60^{\circ} \mathrm{C}$ in the chromogenic agent described earlier. The optimal $\mathrm{pH}$ was determined by measuring the activities in chromogenic agents at different $\mathrm{pH}$ values ranging from $\mathrm{pH} 2$ to $\mathrm{pH} 10$. The $10 \mu \mathrm{L}$ of $\mathrm{GSH}$ with $190 \mu \mathrm{L}$ of DTNB as a control group and all tests were repeated three times. Making a standard curve based on the reaction of different concentrations of GSH and DTNP. In addition, the enzyme activity of DPEP1 was expressed as a decrease in GSH.

\section{Immunohistochemistry Analysis of DPEP1}

DPEP1 polyclonal antibody was prepared with our recombinant DPEP1. The antiserum was harvested from rabbit (Huabio, China) and stored at $-20^{\circ} \mathrm{C}$ for further experiments. For immunohistochemistry analysis, first the $4 \mu \mathrm{m}$ sections were deparaffinized (xylene) and dehydrated (graded alcohols). Second, $0.3 \%$ methanolic hydrogen peroxide solution was added to the sections, and they were incubated in the dark for $10 \mathrm{~min}$ at room temperature and then placed in PBS ( $\mathrm{pH} \mathrm{7.4)} \mathrm{and}$ washed three times for $3 \mathrm{~min}$ each. Third, the sections were placed in Boiled EDTA buffer (Huabio, China) ( $\mathrm{pH} \mathrm{8.0)}$ for

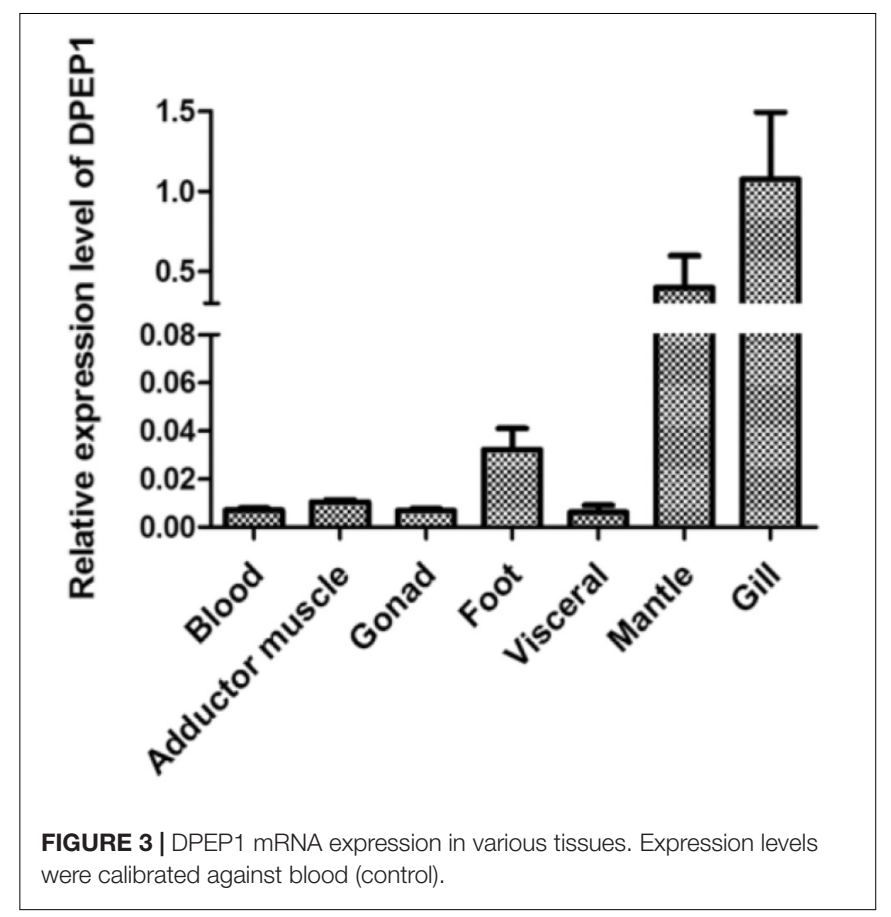

microwave repair for $20 \mathrm{~min}$, then cooled at room temperature for $10 \mathrm{~min}$, placed in PBS ( $\mathrm{pH} \mathrm{7.4)}$ and washed three times for $3 \mathrm{~min}$ each. Fourth, 1\% BSA (Sigma, United States) was added to the sections in the circle drawn with PAP Pen (Zsgb-Bio, China), and the samples were then incubated for $20 \mathrm{~min}$. Fifth, the sections were incubated with primary antibody (DPEP1 antibody dilution at 1:2000) for $1 \mathrm{~h}$ and incubated with secondary antibody using MaxVision ${ }^{\mathrm{TM}}$ HRP-Polymer anti-Rabbit IHC Kit (MaxVision, China) for $15 \mathrm{~min}$ at room temperature. Sixth, DAB (Gene Tech, China) was added to the sections, and the sections were observed under the microscope for approximately $3 \mathrm{~min}$, and then washed with tap water for color termination. Seventh, the sections were dyed with hematoxylin for $4 \mathrm{~min}$, flushed with tap water, dehydrated with gradient alcohol, and made transparent with xylene. Finally, the sections were sealed with a neutral gum. Tissues that were immunohistochemically stained with PBS instead of primary antibody served as negative controls. The immunohistochemical results were analyzed using Image-Pro Plus software and expressed as density mean.

\section{Statistical Analysis}

Means with SDs were used for descriptive statistics throughout the article (mean \pm SD). Data were analyzed and processed by SPSS statistical software. Independent $t$-tests were used to compare with control group. Levels of gene expression in $\mathrm{Cd}^{2+}$ challenges were compared using one factor ANOVA. The protein expression is expressed in density mean. Levels of protein expression were also compared using one factors ANOVA. The relationship between density results and biomolecular results was statistically analyzed by Pearson correlation analysis. Any significant differences 
Song et al.

DEPE1 of Blood Clam

A

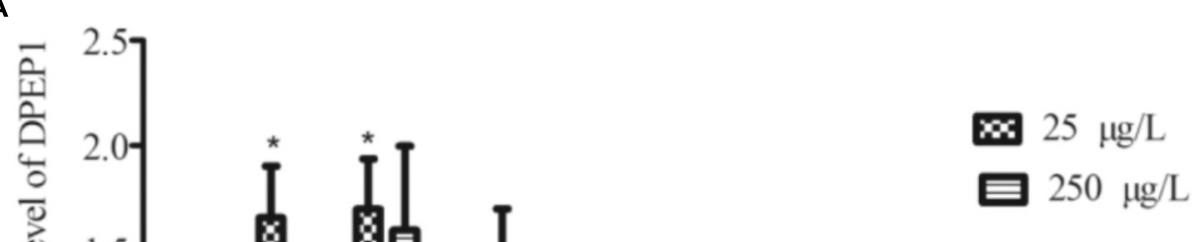

B

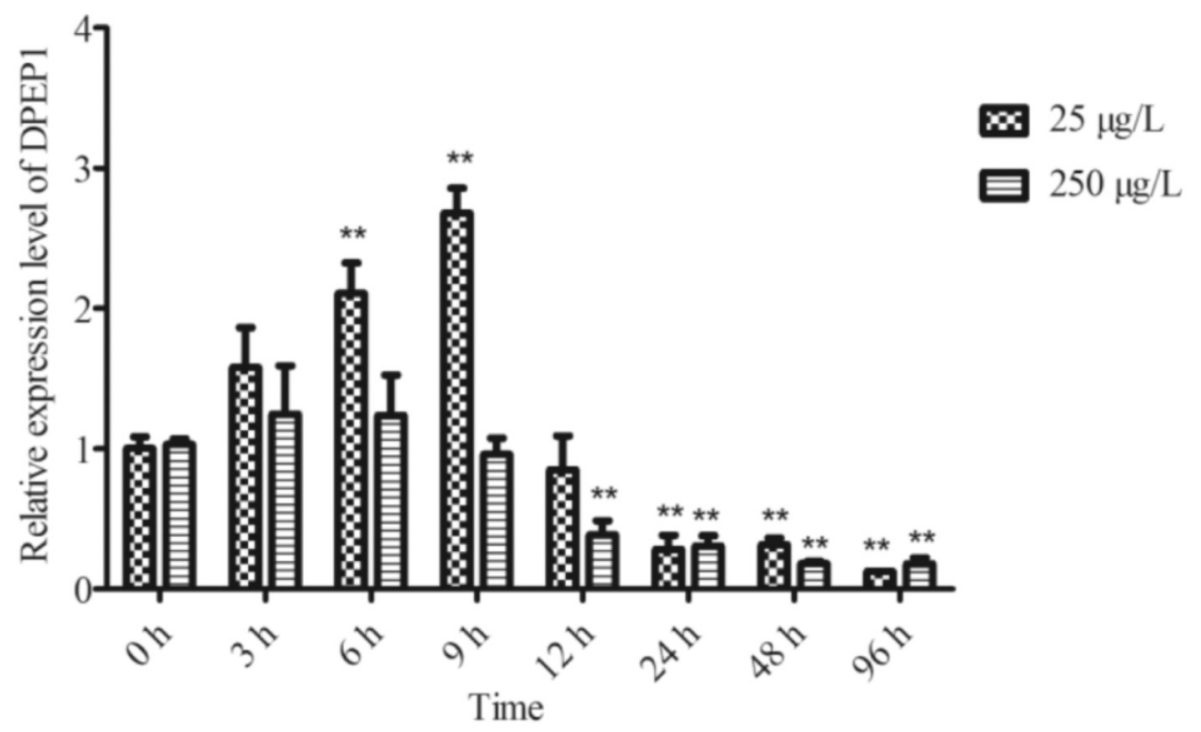

FIGURE 4 | DPEP1 mRA expression after Cd stress. (A) Temporal expression analysis of DPEP1 in gill tissue. (B) Temporal expression analysis of DPEP1 in blood. Asterisks indicate significant difference: ${ }^{*} p<0.05$ and ${ }^{* *} p<0.01$. Control: samples obtained in $0 \mathrm{~h}$.

are indicated with an asterisk at $p<0.05$ and two asterisks at $p<0.01$.

RESULTS

Analysis of the Full-Length eDNA of DPEP1

The full-length eDNA of DPEP1 was $1811 \mathrm{bp}$, including a 5'UTR of $51 \mathrm{bp}$, an ORF of $1359 \mathrm{bp}$ encoding 452 amino acid residues and a $3^{\prime}$ UTR of $401 \mathrm{bp}$ (Figure 1). The predicted MM of the deduced amino acids of DPEP1 was $51 \mathrm{kDa}$, and the theoretical pI was 7.14. TMHMM prediction revealed that a transmembrane region was located in the 30-52th amino acids of DPEP1. Amino acid sequence analysis indicated that a characteristic feature from residues 68-421 belonged to peptidase family M19. BLAST analysis revealed that DPEP1 shared approximately $45-60 \%$ overall identity with counterparts from vertebrates and invertebrates, such as $45 \%$ with Homo sapiens, $49 \%$ with Oryzias latipes, 52\% with Mizuhopecten yessoensis, and 52\% with Crassostrea virginica (Figure 2).

Tissue Expression of the DPEP1 Gene

The results of DPEP1 spatial distribution are shown in Figure 3. The values represent the difference relative to the calibrator tissue (blood). The data show that expression of the mRA transcript

Frontiers in Physiology | www.frontiersin.org

6

July 2018 | Volume 9 | Article 964 


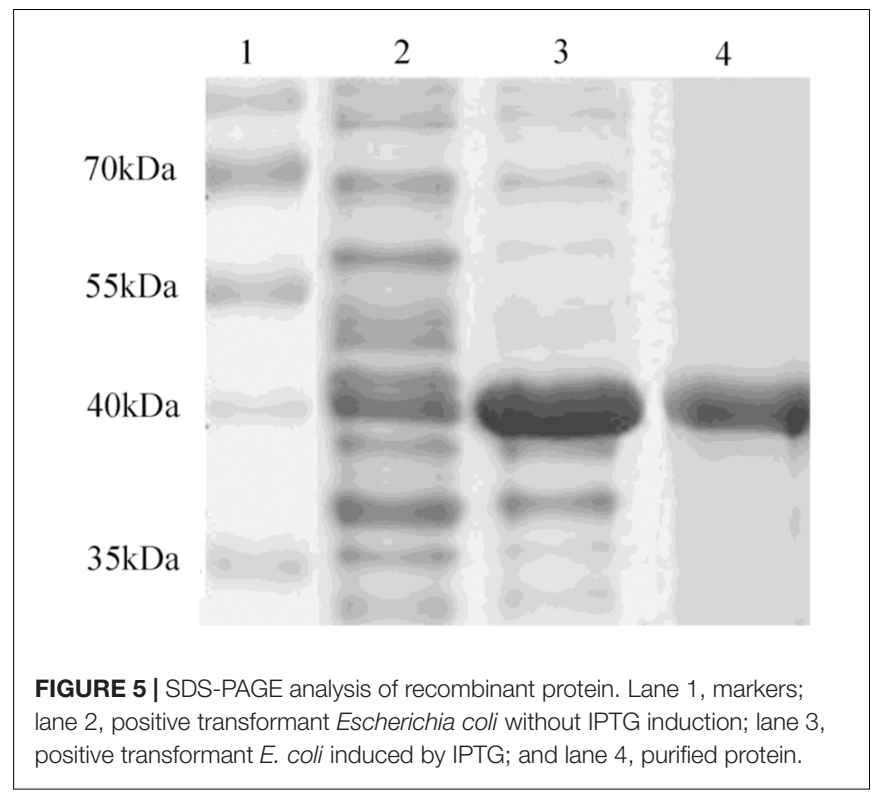

of DPEP1 was detected in all examined tissues, and the mRNA level was most highly expressed in gill and then in mantle, foot, adductor muscle, blood, gonad, and viscera.

\section{Temporal Expression Analysis of DPEP1 after Cd Challenge}

The temporal expression of DPEP1 in gills after Cd stress is shown in Figure 4A. The expression level of DPEP1 mRNA increased in the first $0-9 \mathrm{~h}(p<0.05)$, then it was inhibited from $48 \mathrm{~h}(p<0.05)$, and finally, it maintained a low expression level until to $96 \mathrm{~h}$ under $25 \mu \mathrm{g} / \mathrm{L} \mathrm{Cd}^{2+}$ stress. In addition, it showed no obvious change from 0 to $24 \mathrm{~h}$, then it was inhibited from 48 to $96 \mathrm{~h}(p<0.05)$ under $250 \mu \mathrm{g} / \mathrm{L} \mathrm{Cd}^{2+}$ stress. The temporal expression of DPEP1 in blood after Cd stress is shown in Figure 4B. The expression level of DPEP1 mRNA had no change in the first $0-3 \mathrm{~h}$, then it increased obviously and reached peak expression at $9 \mathrm{~h}(p<0.01)$, then it was inhibited from $24 \mathrm{~h}$ $(p<0.01)$, and finally, it maintained a low expression level until $96 \mathrm{~h}$ under $25 \mu \mathrm{g} / \mathrm{L} \mathrm{Cd}^{2+}$ stress. In addition, it showed no obvious change from 0 to $9 \mathrm{~h}$, then it was inhibited from 48 to $96 \mathrm{~h}$ $(p<0.05)$ under $250 \mu \mathrm{g} / \mathrm{L} \mathrm{Cd}^{2+}$ stress.

\section{Characterization of the Enzymatic Activity of Recombinant DPEP1}

After induction with IPTG, the DPEP1 gene was successfully expressed and it could be purified to homogeneity by Hi-Trap Chelating Columns. The result was revealed by SDS-PAGE (Figure 5). The MM of the purified product was in good agreement with the predicted MM. The enzyme activities of recombinant DPEP1 was shown by a decrease in GSH. At $25^{\circ} \mathrm{C}$, $\mathrm{pH}=7.210 \pm 13.95 \mu \mathrm{g}(n=10)$ of GSH can be hydrolyzed in $1 \mathrm{mg}$ of recombinant DPEP1. The purified recombinant DPEP1 displayed that it was influenced by temperature, and maximum activities were at $30 \sim 40^{\circ} \mathrm{C}$ (Figure 6A). In addition, recombinant DPEP1 showed maximum activities at $\mathrm{pH}=6$ (Figure 6B).

\section{Immunohistochemistry Analysis of DPEP1}

The immunohistochemistry of DPEP1 in tissues is shown in Figure 7. And the protein expression is shown in Figures 8A,B. Immunohistochemistry analysis reviewed that the expression level of DPEP1 protein was the highest in gill and then decreased in mantle, foot, adductor muscle, and viscera. DPEP1 was mainly expressed in epithelial cells at the periphery of the tissue. And it also expressed in some connective tissue and blood sinuses of mantle and viscera. In addition, the expression of DPEP1 in gills was increased at first $12 \mathrm{~h}$ then inhibited until $96 \mathrm{~h}$ $(p<0.05)$ after $25 \mu \mathrm{g} / \mathrm{L} \mathrm{Cd}^{2+}$ stress. Pearson correlation analysis was used to evaluate the relationship between qRT-PCR and immunohistochemistry. There is a linear relationship between the two variables (Figure 8C). According to the Shapiro-Wilk test, it matches the normal distribution $(p>0.05)$, and there is no outlier. There was a strong positive correlation between qRT-PCR and immunohistochemistry, $r=0.767, p<0.001$. The expression trend of DPEP1 at protein level is consistent with the molecular level.

\section{DISCUSSION}

Bivalves have a sedentary and filter-feeding living style, which facilitates the accumulation of pollutants at a high level. Their metal concentration accumulation and integration capabilities and special detoxification capacity has drawn researcher's attention (Engel and Brouwer, 1984; Bebianno and Serafim, 1998; Gao and Wang, 2017). Studies have shown that of the five most common mollusks along the Zhejiang coast in China, T. granosa had the greatest aptitude for the bioaccumulation of Cd (Huang et al., 2007). However, there is a lack of the mechanism study of T. granosa in heavy metal toxicity. In T. granosa, DPEP1 was significantly up-regulated after $250 \mu \mathrm{g} / \mathrm{L}$ Cd challenge based on iTRAQ proteome analysis in our previous study (Bao et al., 2016), which suggests that DPEP1 might be involved in Cd-induced responses.

In this study, the full-length cDNA of $T$. granosa DPEP1 was cloned for the first time. Amino acid sequence analysis indicated that DPEP1 possessed a structural domain belonging to peptidase family M19 (membrane dipeptidase family, clan MJ) and a hydrophobic region at the carboxylic end of its membrane-bound region. These results are consistent with those other reported DPEP1 sequences (Adachi et al., 1993; Nitanai et al., 2002). DPEP1 is a membrane-bound dipeptidase involved in the degradation of surrounding extracellular matrix components (Mciver et al., 2004). Immunohistochemistry showed that the DPEP1 is mainly expressed in the epithelium. These results are similar to those of human DPEP1 (Inamura et al., 1994). This finding also suggests that DPEP1 may be responsible for the degradation of tissue basement membranes. Therefore, an increase in DPEP1 protein may allow heavy metals to move into the body more easily.

The enzymatic activity of recombinant DPEP1 showed that it can hydrolyze GSH. These results confirmed that DPEP1 plays important roles in the metabolism of GSH and its conjugates 

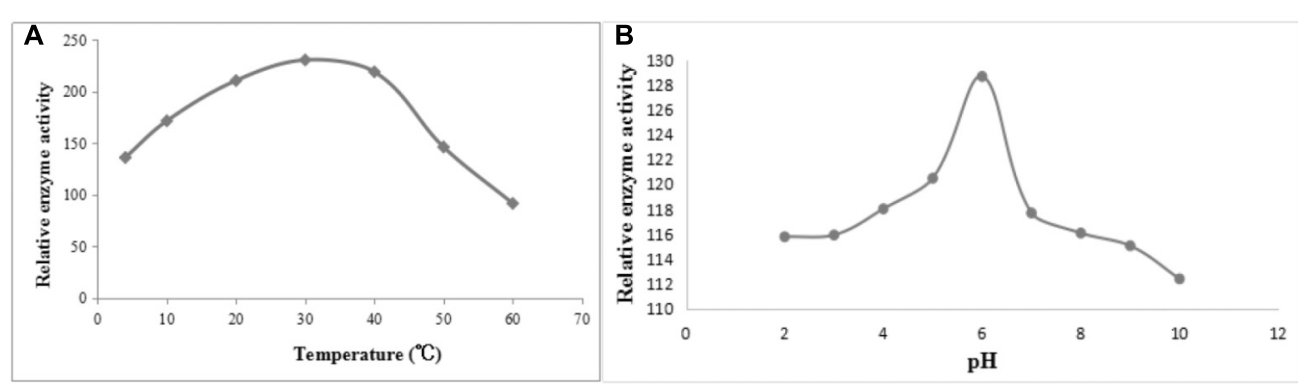

FIGURE 6 | Determination of enzyme activity of recombinant protein. (A) Effect of temperature on the enzyme activity of recombinant protein. (B) Effect of pH on the enzyme activity of recombinant protein.

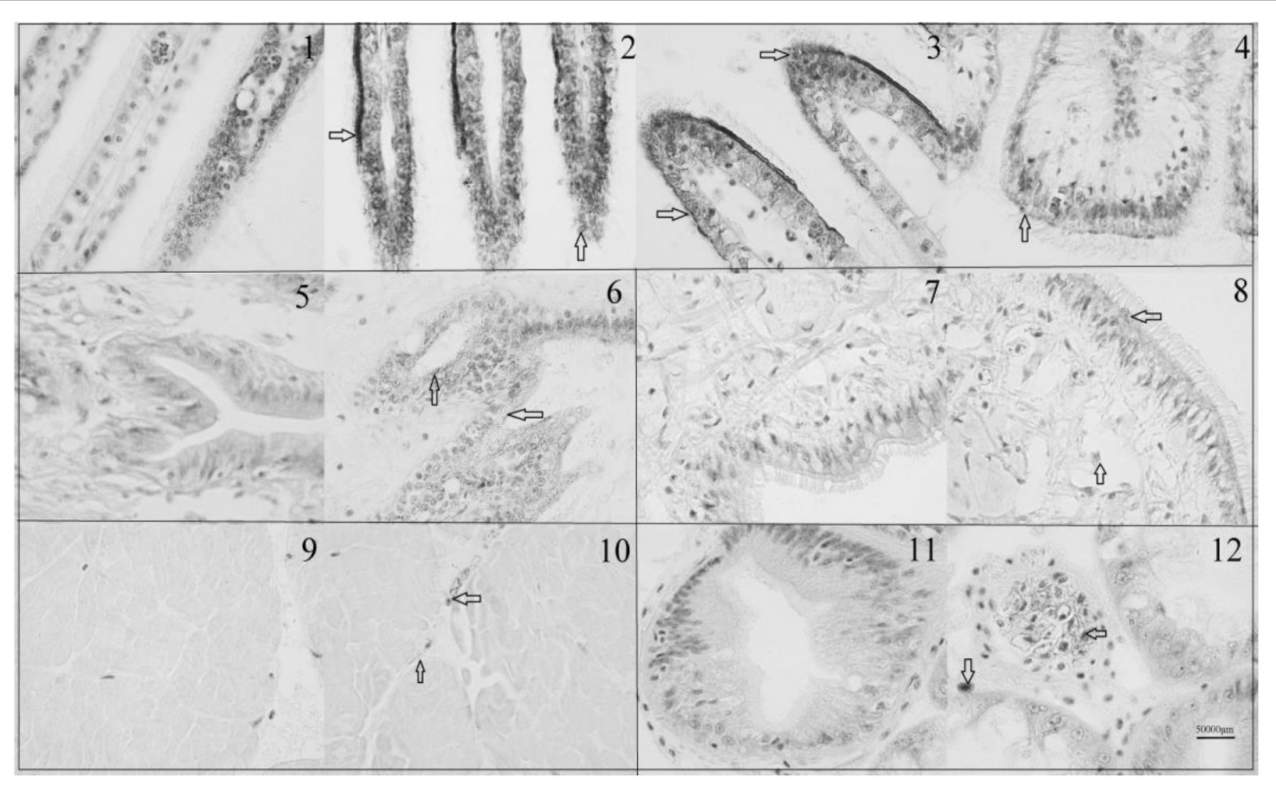

FIGURE 7 | Immunohistochemistry of DPEP1. Tissue was observed under 1000 times microscopes. (1) Negative control of gills at $0 \mathrm{~h}$, (2) gills at $0 \mathrm{~h}$, (3) gills after $12 \mathrm{~h}$ of $25 \mu \mathrm{g} / \mathrm{L} \mathrm{Cd}$ stress, (4) gills after $96 \mathrm{~h}$ of $25 \mu \mathrm{g} / \mathrm{L}$ Cd stress, (5) negative control of mantle, (6) mantle at $0 \mathrm{~h}$, (7) negative control of foot (8) foot at $0 \mathrm{~h}$, (9) negative control of adductor muscle, (10) adductor muscle at $0 \mathrm{~h},(11)$ negative control of viscera, and (12) viscera at $0 \mathrm{~h}$. The DPEP1 protein is expressed in the brown part of the arrowhead. The same organization is marked with a black box.

(Hooper et al., 1987; Adachi et al., 1990). GSH is widely distributed and is a primary intracellular antioxidant agent (Kidd, 1997). Its thiol (SH-) group on the cysteine residue can scavenge free radicals (Noctor and Foyer, 1998; Dickinson and Forman, 2002). Cd is unable to generate reactive oxygen species (ROS) directly, but Cd-induced oxidative stress is a common phenomenon observed in multiple studies (Dorta et al., 2003; Belyaeva et al., 2006). Therefore, GSH is one of the most important metabolites when dealing with Cd-induced oxidative stress. Due to the thiol groups in GSH, sulfhydryl reactive metals, such as Cd, can easily bind to them to form Cd-GSH (Ercal et al., 2001; Hansen et al., 2006). Complexation by GSH makes free $\mathrm{Cd}$ unavailable for cell metabolism, preventing $\mathrm{Cd}$ interaction with critical cellular targets, and blocking the mechanisms leading to Cd-induced oxidative stress (Kamiyama et al., 1995; Rana and Verma, 1996; Waisberg et al., 2003). Therefore, during Cd stress, GSH not only neutralizes ROS but also detoxifies
Cd directly (Vairavamurthy et al., 2000; Thévenod, 2003). So the change of GSH content plays an important role in the detoxification of cadmium. In addition, studies have found that oxidative stress is related to the SNPs of GSH metabolism-related genes, including DPEP1 (Bowers et al., 2010). Reduced DPEP1 expression has been found to lead to the dysregulation of GSH homeostasis, which affects the maintenance of an optimal redox state in the cellular microenvironment and protects cells against pathological stress (Klaunig et al., 1998; Zhang et al., 2012). These results show that DPEP1 can affect the oxidative stress of the body through the metabolism of GSH. DPEP1 may involve in cadmium stress response on the body by balancing GSH.

Tissue expression analysis by real-time PCR demonstrated that DPEP1 mRNA was expressed in all studied tissues and that it showed the highest expression level in gills and then the next-highest expression in mantle, and immunohistochemistry 

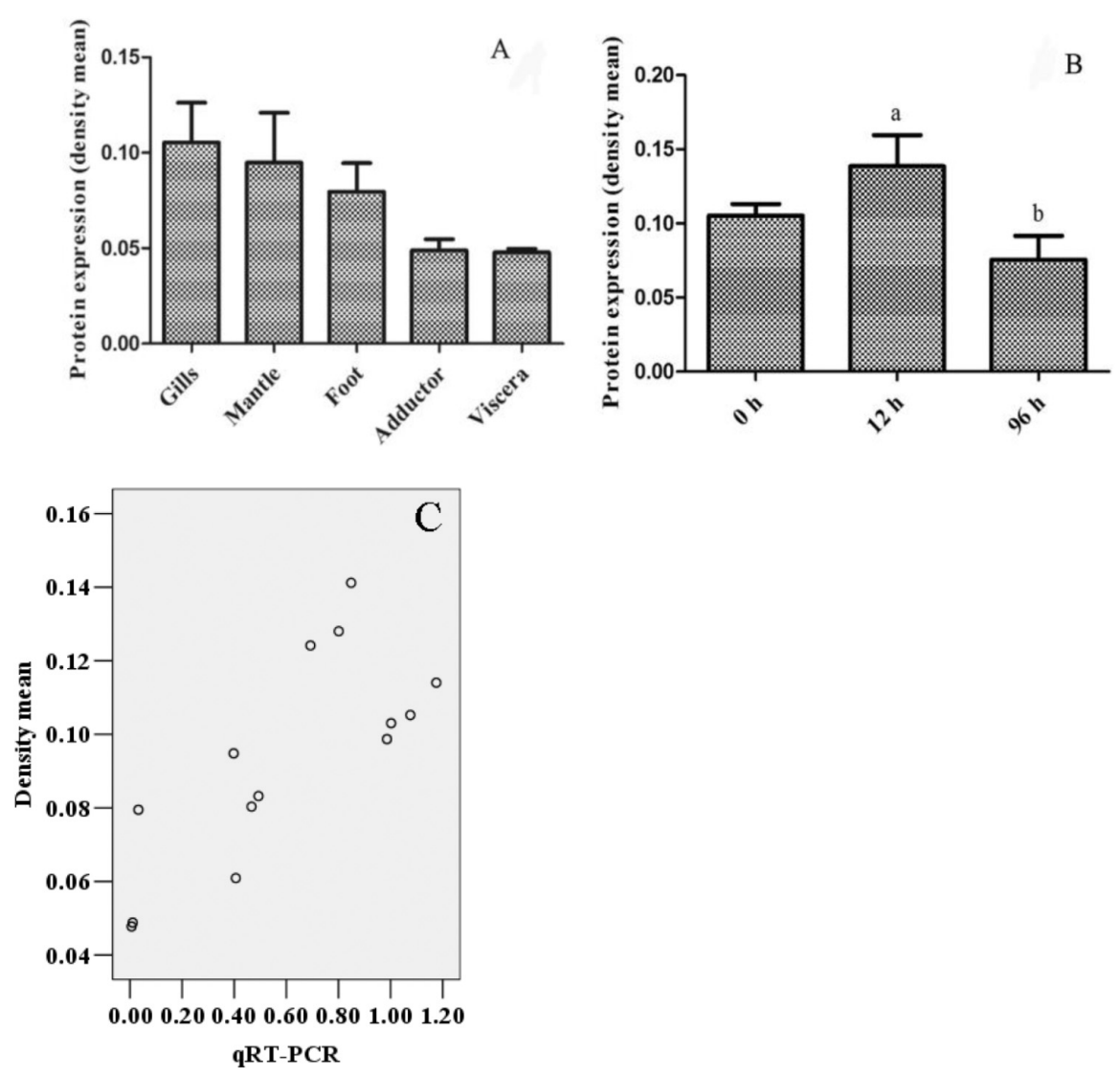

FIGURE 8 | The quantized value of immunohistochemistry $(n=3)$ and a scatter diagram. (A) The density mean of various tissues. (B) The density mean of gills in different time after $25 \mu \mathrm{g} / \mathrm{L} \mathrm{Cd} 2^{+}$stress. The 12 and $96 \mathrm{~h}$ are significant difference $(p<0.05)$. (C) The scatter diagram of densitometric analysis results with biomolecular analysis results.

analysis presented the same distribution at protein level. Gills are the likely primary entry point of waterborne $\mathrm{Cd}$ and the main organ for enriching heavy metals in the short term (Domouhtsidou and Dimitriadis, 2000; Paul-Pont et al., 2010). Gills are important in the modulation and clearance of cadmium (Haberkorn et al., 2010). Various damages to gills have also been reported in the mussel Mytilus galloprovincialis Lam after Cd stress (Viarengo et al., 1985; Fernandez et al., 2010). Many studies have also shown that genes related to cadmium detoxification in T. granosa have a higher expression level in gills (Bao et al., 2016; Qian et al., 2017). The higher transcriptional expression in gills and mantle suggests that DPEP1 may associate with the response to Cd. Additionally, the universal expression of DPEP1 suggests that it might be involved in various metabolic pathways. Temporal expression analysis by real-time PCR demonstrated that DPEP1 mRNA expression peaked in the initial stage, which was followed by a decline, and finally, inhibition after Cd stress at either 25 or $250 \mu \mathrm{g} / \mathrm{L}$ in two tested tissues. This result is similar to metallothioneins (MT) expression in Crassostrea hongkongensis after Cd stress (Xu et al., 2015). In addition, immunohistochemistry analysis in gills after $25 \mu \mathrm{g} / \mathrm{L}$ $\mathrm{Cd}$ stress also presented the same trend at the protein level. In addition, after Cd stress, the highest expression difference was in the viscera. GSH is mainly synthesized in the viscera, and its synthesis is fast and sensitive (Kamiyama et al., 1995; Liu et al., 1995). When cadmium enters the body, it is enriched in the liver, resulting in high GSH expression. Therefore, DPEP1 is also increased in liver. From this result, we speculate that during initial exposure, the host was in its active defense state; when its cells were oxidatively challenged, it attempted to maintain a redox balance in the internal environment and GSH synthesis increased, resulting in increased expression of DPEP1. After a period of exposure, in order to keep the higher content of GSH, the expression of DPEP1 decreased, and finally, its expression was inhibited. That is, when cadmium stress occurs, the body produces a large number of ROS; in order to reduce the resulting oxidation loss, GSH content will increase until a dynamic balance is maintained, resulting in changes in the expression of DPEP1. These facts suggest that DPEP1 is involved in cadmium stress response by balancing GSH in T. granosa.

In summary, the coding sequence of DPEP1 from T. granosa was elucidated for the first time. DPEP1 and its Cd response-related functions in T. granosa were investigated by molecular and protein approaches in this study. Our data demonstrate the differential expression of DPEP1 in various 
organs. In addition, low expression of DPEP1 may protect T. granosa after Cd stress. DPEP1 is involved in GSH metabolism and may change cell membrane permeability. The function and mechanism of DPEP1 in Cd stress in T. granosa should be further studied.

\section{AUTHOR CONTRIBUTIONS}

YB conceived and designed the experiments. DS, CL, and YY performed the experiments. DS, ZL, and GQ analyzed the data. DS, CL, and GQ contributed reagents, materials, and analysis

\section{REFERENCES}

Adachi, H., Katayama, T., Nakazato, H., and Tsujimoto, M. (1993). Importance of Glu-125 in the catalytic activity of human renal dipeptidase. Biochim. Biophys. Acta 1163, 42-48. doi: 10.1016/0167-4838(93)90276-W

Adachi, H., Tawaragi, Y., Inuzuka, C., Kubota, I., Tsujimoto, M., Nishihara, T., et al. (1990). Primary structure of human microsomal dipeptidase deduced from molecular cloning. J. Biol. Chem. 265, 3992-3995.

Bagchi, D., Bagchi, M., Hassoun, E. A., and Stohs, S. J. (1996). Cadmium-induced excretion of urinary lipid metabolites, DNA damage, glutathione depletion, and hepatic lipid peroxidation in sprague-dawley rats. Biol. Trace Elem. Res. 52, 143-154. doi: 10.1007/BF02789456

Bao, Y., Liu, X., Zhang, W., Cao, J., Li, W., Li, C., et al. (2016). Identification of a regulation network in response to cadmium toxicity using blood clam Tegillarca granosa as model. Sci. Rep. 6:35704. doi: 10.1038/srep35704

Bao, Y., Zhang, L., Dong, Y., and Lin, Z. (2014). Identification and comparative analysis of the Tegillarca granosa haemocytes microRNA transcriptome in response to $\mathrm{Cd}$ using a deep sequencing approach. PLoS One 9:e93619. doi: 10.1371/journal.pone.0093619

Bebianno, M. J., and Serafim, M. A. (1998). Comparison of metallothionein induction in response to cadmium in the gills of the bivalve molluscs Mytilus galloprovincialis and Ruditapes decussatus. Sci. Total Environ. 214, 123-131. doi: 10.1016/S0048-9697(98)00059-X

Belyaeva, E. A., Dymkowska, D., Wieckowski, M. R., and Wojtczak, L. (2006). Reactive oxygen species produced by the mitochondrial respiratory chain are involved in $\mathrm{Cd} 2+$-induced injury of rat ascites hepatoma AS-30D cells. Biochim. Biophys. Acta 1757, 1568-1574. doi: 10.1016/j.bbabio.2006. 09.006

Bowers, K., Newschaffer, C., Bressler, J. P., and Fallin, M. D. (2010). "Interaction between gluathione genes and maternal oxidative stress on risk for ASD," in Proceedings of the International Meeting for Autism Research, (San Francisco, CA).

Chen, C., Shen, W., Gu, H., Wu, L., Lin, L., and Xue, Q. (2017). Vitellogenin's putative role in Tegillarca granosa's cadmium detoxification. Genes Genom. 39, 143-154. doi: 10.1007/s13258-016-0477-4

Cheng, X., Jiang, G., Chai, X., and Teng, S. (2016). Full-length cDNA cloning and expression analysis of glutathione peroxidase from blood clam Tegillarca granosa. Acta Hydrobiol. Sin. 40, 1144-1151.

Clemens, S. (2006). Toxic metal accumulation, responses to exposure and mechanisms of tolerance in plants. Biochimie 88, 1707-1719. doi: 10.1016/j. biochi.2006.07.003

Cuypers, A., Plusquin, M., Remans, T., Jozefczak, M., Keunen, E., Gielen, H., et al. (2010). Cadmium stress: an oxidative challenge. Biometals 23, 927-940. doi: 10.1007/s10534-010-9329-x

Dickinson, D. A., and Forman, H. J. (2002). Cellular glutathione and thiols metabolism. Biochem. Pharmacol. 64, 1019-1026. doi: 10.1016/S0006-2952(02) 01172-3

Domouhtsidou, G. P., and Dimitriadis, V. K. (2000). Ultrastructural localization of heavy metals $(\mathrm{Hg}, \mathrm{Ag}, \mathrm{Pb}$, and $\mathrm{Cu})$ in gills and digestive gland of mussels, Mytilus galloprovincialis. Arch. Environ. Con. Tox. 38, 472-478. doi: 10.1007/ s002449910062

Dorta, D. J., Leite, S., Demarco, K. C., Imr, P., Rodrigues, T., and Mingatto, F. E. (2003). A proposed sequence of events for cadmium-induced mitochondrial tools. YB and DS wrote the paper. All authors reviewed the manuscript.

\section{FUNDING}

This research was supported by the National Science Foundation of China (31672678), Zhejiang Major Program of Science and Technology (2016C02055-9), Ningbo Science and Technology International Cooperation Research Projects (2016D10017), and the K. C. Wong Magna Fund at Ningbo University.

impairment. J. Inorg. Biochem. 97, 251-257. doi: 10.1016/S0162-0134(03) 00314-3

Eisenach, P. A., Soeth, E., Röder, C., Klöppel, G., Tepel, J., Kalthoff, H., et al. (2013). Dipeptidase 1 (dpep1) is a marker for the transition from low-grade to high-grade intraepithelial neoplasia and an adverse prognostic factor in colorectal cancer. Br. J. Cancer 109, 694-703. doi: 10.1038/bjc.2013.363

Engel, D. W., and Brouwer, M. (1984). Trace metal-binding proteins in marine molluscs and crustaceans. Mar. Environ. Res 13, 177-194. doi: 10.1016/01411136(84)90029- 1

Ercal, N., Gurerorhan, H., and Aykinburns, N. (2001). Toxic metals and oxidative stress part i: mechanisms involved in metal-induced oxidative damage. Cur. Top. Med. Chem. 1, 529-539. doi: 10.2174/1568026013394831

Fernandez, B., Campillo, J. A., Martinez-Gomez, C., and Benedicto, J. (2010). Antioxidant responses in gills of mussel (Mytilus galloprovincialis) as biomarkers of environmental stress along the spanish mediterranean coast. Aquat. Toxicol. 99, 186-197. doi: 10.1016/j.aquatox.2010.04.013

Gao, X., and Wang, Y. (2017). Advances in the studies on functional genes of molluscs under cadmiun stress. J. Agric. Univ. 22, 122-130. doi: 10.11841/j.issn. 1007-4333

Gong, Q., Cai, Y. Q., Ma, B., Yu, H. J., Qian, B. L., Wang, Y., et al. (2011). On heavy metal sanitation standards of bivalve molluscs. Mar. Fish. 33, 226-233. doi: 10.13233/j.cnki.mar.fish.2011.02.002

Haberkorn, H., Lambert, C., Le Goïc, N., Guéguen, M., Moal, J., Palacios, E., et al. (2010). Effects of alexandrium minutum exposure upon physiological and hematological variables of diploid and triploid oysters, crassostreagigas. Aquat. Toxicol. 97, 96-110. doi: 10.1016/j.aquatox.2009.12.006

Hansen, J. M., Zhang, H., and Jones, D. P. (2006). Differential oxidation of thioredoxin 1, thioredoxin 2 and glutathione by meta ions. Free Radic. Biol. Med. 40, 138-145. doi: 10.1016/j.freeradbiomed.2005.09.023

Henson, M. C., and Anderson, M. B. (2000). The effects of cadmium on placental endocrine function. Recent Res. Dev. Endocrinol. 1, 37-47.

Hooper, N. M., Low, M. G., and Turner, A. J. (1987). Renal dipeptidase is one of the membrane proteins released by phosphatidylinositol-specific phospholipase C. Biochem. J. 244, 465-469. doi: 10.1042/bj2440465

Huang, H., Wu, J. Y., and Wu, J. H. (2007). Heavy metal monitoring using bivalved shellfish from Zhejiang coastal waters, east china sea. Environ. Monit. Assess. 129, 315-320. doi: 10.1007/s10661-006-9364-9

Hui, T., Wang, J., and Zhu, Y. (2001). Effects of Cd on hepatic GSH metabolism in Tilapia nilotica. J. Zhejiang Univ. Agric. Life Sci. 27, 575-578.

Hwang, D. S., Lee, K. W., Han, J., Park, H. G., Lee, J., Lee, Y. M., et al. (2010). Molecular characterization and expression of vitellogenin $(\mathrm{Vg})$ genes from the cyclopoid copepod, Paracyclopina nana exposed to heavy metals. Comp. Biochem. Physiol. C Toxicol. Pharmacol. 151, 360-368. doi: 10.1016/j.cbpc.2009. 12.010

Inamura, T., Pardridge, W. M., Kumagai, Y., and Black, K. L. (1994). Differential tissue expression of immunoreactive dehydropeptidase I, a peptidyl leukotriene metabolizing enzyme. Prostaglandins Leukot. Essent. Fatty Acids 50, 85-92. doi: 10.1016/0952-3278(94)90152-X

Kamiyama, T., Miyakawa, H., Li, J. P., Akiba, T., Liu, J. H., Liu, J., et al. (1995). Effects of one-year cadmium exposure on livers and kidneys and their relation to glutathione levels. Res. Commun. Pathol. Pharmacol. 88, 177-186.

Karmakar, R., Banik, S., Bandyopadhyay, S., and Chatterjee, M. (1998). Cadmiuminduced alterations of hepatic lipid peroxidation, glutathione $S$-transferase 
activity and reduced glutathione level and their possible correlation with chromosomal aberration in mice: a time course study. Mutat. Res. 397, 183-190. doi: 10.1016/S0027-5107(97)00209-1

Kidd, P. M. (1997). Glutathione: systemic protectant against oxidative and free radical damage. Altern. Med. Rev. 2, 155-176.

Klaunig, J. E., Xu, Y., Isenberg, J. S., Bachowski, S., Kolaja, K. L., Jiang, J., et al. (1998). The role of oxidative stress in chemical carcinogenesis. Annu. Rev. Pharmacol. 106, 289-295. doi: 10.1146/annurev.pharmtox.44.101802.121851

Kozak, E. M., and Tate, S. S. (1982). Glutathione-degrading enzymes of microvillus membranes. J. Biol. Chem. 257, 6322-6327.

Li, P., Lin, Z., and Bao, Y. (2015). A novel tissue inhibitor of metalloproteinase 3 in blood clam Tegillarca granose: molecular cloning and immune-related research of Cd. J. Fish. 39, 336-344.

Liu, G. X., Chai, X. L., Shao, Y. Q., and Wu, H. X. (2012). Specific death symptoms and organic lesions of blood clam Tegillarca granosa in acute copper, zinc, lead and cadmium exposures. Adv. Mat. Res. 518-523, 490-493. doi: 10.4028/www. scientific.net/AMR.518-523.490

Liu, J. H., Miyakawa, H., Takano, T., Marumo, F., and Sato, C. (1995). Effects of cadmium on glutathione metabolism in Hep G2 cells. Res. Commun. Mol. Path. 90, 143-152.

Liu, X., Wang, X., and He, Q. (2001). Wide on the hepatic and renal toxicity of cadmium and glutathione content of the relationship. J. Toxicol. 15, 31-32. doi: 10.16421/j.cnki.1002-3127.2001.01.013

Livak, K. J., and Schmittgen, T. D. (2001). Analysis of relative gene expression data using real-time quantitative PCR and the 2- $\Delta \Delta$ CT method. Method. 25, 402-408. doi: 10.1006/meth.2001.1262

Love, R. R., Duc, N. B., Havighurst, T. C., Mohsin, S. K., Zhang, Q., DeMets, D. L., et al. (2003). Her-2/neu overexpression and response to oophorectomy plus tamoxifen adjuvant therapy in estrogen receptor-positive premenopausal women with operable breast cancer. J. Clin. Oncol. 21, 453-457. doi: 10.1200/ JCO.2003.10.133

Mciver, C. M., Lloyd, J. M., Hewett, P. J., and Hardingham, J. E. (2004). Dipeptidase 1: a candidate tumor-specific molecular marker in colorectal carcinoma. Cancer Lett. 209, 67-74. doi: 10.1016/j.canlet.2003.11.033

Meister, A. (1994). Glutathione, ascorbate, and cellular protection. Cancer Res. 54, 1969s-1975s.

Nakagawa, H., Inazawa, J., Inoue, K., Misawa, S., Kashima, K., Adachi, H., et al. (1992). Assignment of the human renal dipeptidase gene (dpep1) to band q24 of chromosome 16. Cytogenet. Cell Genet. 59, 258-260. doi: 10.1159/000133263

Nasreddine, L., and Parent-Massin, D. (2002). Food contamination by metals and pesticides in the European Union. should we worry? Toxicol. Lett. 127, 29-41. doi: 10.1016/S0378-4274(01)00480-5

Nitanai, Y., Satow, Y., Adachi, H., and Tsujimoto, M. (2002). Crystal structure of human renal dipeptidase involved in beta-lactam hydrolysis. J. Mol. Biol. 321, 177-184. doi: 10.1016/S0022-2836(02)00632-0

Noctor, G., and Foyer, C. H. (1998). Ascorbate and glutathione: keeping active oxygen under control. Annu. Rev. Plant Physiol. Plant Mol. Biol. 49, 249-279. doi: 10.1146/annurev.arplant.49.1.249

Okamoto, T., Matsumura, N., Mandai, M., Oura, T., Yamanishi, Y., Horiuchi, A., et al. (2011). Distinguishing primary from secondary mucinous ovarian tumors: an algorithm using the novel marker dpepl. Mod. Pathol. 24, 267-276. doi: 10.1038/modpathol.2010.204

Pathak, N., and Khandelwal, S. (2006). Oxidative stress and apoptotic changes in murine splenocytes exposed to cadmium. Toxicology 220, 26-36. doi: 10.1016/ j.tox.2005.11.027

Paul-Pont, I., Gonzalez, P., Baudrimont, M., Jude, F., Raymond, N., Bourrasseau, L., et al. (2010). Interactive effects of metal contamination and pathogenic organisms on the marine bivalve Cerastoderma edule. Mar. Pollut. Bull. 158, 3401-3410. doi: 10.1016/j.marpolbul.2009.11.013

Peng, C., Zhao, X., Han, Y., Shi, W., Liu, S., and Liu, G. (2015). Toxic effects of chronic sub-lethal $\mathrm{Cu} 2+, \mathrm{Pb} 2+$ and $\mathrm{Cd} 2+$ on antioxidant enzyme activities in various tissues of the blood cockle, anadara granosa. J. Residuals Sci. Tech. 12, 125-131. doi: 10.12783/issn.1544-8053/12/3/2

Peng, M. (2014). Detoxification mechanism of GSH on Cd. J. Technol. Dongguan Univ. 21, 69-73.

Qian, G., Bao, Y., Li, C., Xie, Q., Lu, M., and Lin, Z. (2017). Nfu1 mediated ros removal caused by cd stress in Tegillarca granosa. Front. Physiol. 8:1061. doi: $10.3389 /$ fphys.2017.01061
Rana, S. V., and Verma, S. (1996). Protective effects of GSH, vitamin E, and selenium on lipid peroxidation in cadmium fed rats. Biol. Trace Elem. Res. 51, 161-168. doi: 10.1007/BF02785435

Schlenk, D., and Rice, C. D. (1998). Effect of zinc and cadmium treatment on hydrogen peroxide-induced mortality and expression of glutathione and metallothionein in a teleost hepatoma cell line. Aquat. Toxicol. 43, 121-129. doi: 10.1016/S0166-445X(98)00050-2

Shi, W., Guan, X., Han, Y., Guo, C., Rong, J., Su, W., et al. (2018). Waterborne $\mathrm{Cd} 2+$, weakens the immune responses of blood clam through impacting $\mathrm{Ca} 2+$, signaling and $\mathrm{Ca} 2+$, related apoptosis pathways. Fish Shellfish Immunol. 77, 208-213. doi: 10.1016/j.fsi.2018.03.055

Shi, W., Zhao, X., Han, Yu, Che, Z., Chai, X., Liu, G., et al. (2016). Ocean acidification increases cadmium accumulation in marine bivalves: a potential threat to seafood safety. Sci. Rep. 6:20197. doi: 10.1038/srep 20197

Tachibana, K., Saito, M., Imai, J. I., Ito, E., Yanagisawa, Y., Honma, R., et al. (2017). Clinicopathological examination of dipeptidase 1 expression in colorectal cancer. Biomed. Rep. 6, 423-428. doi: 10.3892/br.2017.870

Thévenod, F. (2003). Nephrotoxicity and the proximal tubule. Nephron Physiol. 93, 87-93. doi: 10.1159/000070241

Vairavamurthy, M. A., Goldenberg, W. S., Ouyang, S., and Khalid, S. (2000). The interaction of hydrophilic thiols with cadmium: investigation with a simple model, 3-mercaptopropionic acid. Mar. Chem. 70, 181-189. doi: 10.1016/ S0304-4203(00)00023-2

Vethanayagam, J. G. G., Green, E. H., Rose, R. C., and Bode, A. M. (1999). Glutathione-dependent ascorbate recycling activity of rat serum albumin. Free Radic. Biol. Med. 26, 1591-1598. doi: 10.1016/S0891-5849(99)00031-3

Viarengo, A., Palmero, S., Zanicchi, G., Capelli, R., Vaissiere, R., and Orunesu, M. (1985). Role of metallothioneins in $\mathrm{Cu}$ and $\mathrm{Cd}$ accumulation and elimination in the gill and digestive gland cells of Mytilus galloprovincialis Lam. Mar. Environ. Res. 16, 23-36. doi: 10.1016/0141-1136(85)90018-2

Waisberg, M., Joseph, P., and Hale, B. (2003). Molecular and cellular mechanisms of cadmium carcinogenesis. Toxicol. 192, 95-117. doi: 10.1016/S0300-483X(03) 00305-6

Wang, Z., Wu, H., Chen, Q., and Gao, Y. (2013). Effects of age and environmental conditions on the accumulation of heavy metals $\mathrm{Cd}$ and $\mathrm{Cu}$ in Tegillarca granosa. Acta Ecol. Sin. 33, 6869-6875. doi: 10.5846/stxb201207020922

Wang, Z., Wu, H., Wang, Y., Zhou, C., and Chen, Q. (2014). Acute toxic and joint toxic experiments of $\mathrm{Cd} \sim(2+)$ and $\mathrm{Cu} \sim(2+)$ on Tegillarca granosa. Mar. sci. 38, 16-20. doi: 10.11759/hykx20130524001

Xu, D., Yu, B., Zhang, Y., Cui, M., and Zhang, Q. (2015). Metallothionein protein expression of Crassostrea hongkongensis in response to cadmium stress. J. Shellfish Res. 34, 311-318. doi: 10.2983/035.034. 0213

Yang, H., Liu, N., Li, Y., Wei, X., and Wang, L. (2015). Effects of cadmium on glutathione contents and activities of glutathione related enzymes in gill and hepatopancreas of Anodonta woodiana. J. Agric. Sci. Camb. 34, 15-21. doi: 10.11654/jaes.2015.01.003

Zhang, G., Schetter, A., He, P., Funamizu, N., Gaedcke, J., Ghadimi, B. M., et al. (2012). Dpep1 inhibits tumor cell invasiveness, enhances chemosensitivity and predicts clinical outcome in pancreatic ductal adenocarcinoma. PLoS One 7:e31507. doi: 10.1371/journal.pone.0031507

Zhou, J., Li, C. H., Li, Y., Su, X. R., and Li, T. W. (2013). cDNA cloning and mRNA expression of heat shock protein 70 gene in blood clam Tegillarca granosa against heavy metals challenge. Afr. J. Biotechnol. 12, 2341-2352. doi: 10.5897/AJB12.1624

Conflict of Interest Statement: The authors declare that the research was conducted in the absence of any commercial or financial relationships that could be construed as a potential conflict of interest.

Copyright (c) 2018 Song, Lin, Yuan, Qian, Li and Bao. This is an open-access article distributed under the terms of the Creative Commons Attribution License (CC BY). The use, distribution or reproduction in other forums is permitted, provided the original author(s) and the copyright owner(s) are credited and that the original publication in this journal is cited, in accordance with accepted academic practice. No use, distribution or reproduction is permitted which does not comply with these terms. 